\title{
On the Verge of a Catastrophic Collapse? The Need for a Multi- Ecosystem Approach to Microbiome Studies
}

OPEN ACCESS

Edited by:

Andrés Moya,

University of Valencia,

Spain

Reviewed by:

Fernando Baquero,

Ramón y Cajal Institute for Health

Research, Spain

Luis Delaye,

Instituto Politécnico Nacional de

México (CINVESTAV), Mexico

*Correspondence:

Olaf F. A. Larsen

o.f.a.larsen@vu.ni

Specialty section:

This article was submitted to

Microbial Symbioses,

a section of the journal

Frontiers in Microbiology

Received: 28 September 2021 Accepted: 02 November 2021

Published: 02 December 2021

Citation:

Larsen OFA and van de Burgwal LHM (2021) On the Verge of a Catastrophic Collapse? The Need for a Multi-Ecosystem Approach to Microbiome Studies.

Front. Microbiol. 12:784797.

doi: 10.3389/fmicb.2021.784797

\section{Olaf F. A. Larsen* and Linda H. M. van de Burgwal}

Athena Institute for Research on Innovation and Communication in Health and Life Sciences, Vrije Universiteit Amsterdam, Amsterdam, Netherlands

While the COVID-19 pandemic has led to increased focus on pathogenic microbes that cross the animal-human species barrier, calls to include non-pathogenic interactions in our perspective on public health are gaining traction in the academic community. Over generations, the diversity of the human gut microbiota is being challenged by external perturbations and reduced acquisition of symbiotic species throughout life. When such reduced diversity concerns not only the microbial species, but also the higher taxonomic levels and even the guild level, adequate compensation for possible losses may be lacking. Shifts from a high-abundance to a low-abundance state, known as a tipping point, may result in simultaneous shifts in covarying taxa and ultimately to a catastrophic collapse in which the ecosystem abruptly and possibly irreversibly shifts to an alternative state. Here, we propose that co-occurrence patterns within and between microbial communities across human, animal, soil, water, and other environmental domains should be studied in light of such critical transitions. Improved mechanistic understanding of factors that shape structure and function is needed to understand whether interventions can sustainably remodel disease-prone microbiota compositions to robust and resilient healthy microbiota. Prerequisites for a rational approach are a better understanding of the microbial interaction network, both within and inter-domain, as well as the identification of early warning signs for a catastrophic collapse, warranting a timely response for intervention. We should not forget that mutualism and pathogenicity are two sides of the same coin. Building upon the planetary health concept, we argue that microbiome research should include system level approaches to conserve ecosystem resilience.

\section{HIGHLIGHTS}

1. Non-pathogenic interactions between ecosystems play a key role in maintaining health.

2. The human gut microbiome may be on the verge of a catastrophic collapse.

3. Research should identify keystone taxa and guilds that interconnect different domains.

4. We should not forget that mutualism and pathogenicity are two sides of the same coin.

Keywords: transitions, catastrophic collapse, planetary health, keystone taxa, microbial guilds 


\section{INTRODUCTION}

Host-microbe interactions have primarily been studied from a perspective of pathogenicity, and in light of COVID-19, attention has focused on a range of pathogenic microbes that cross the animal-human species barrier. Indeed, zoonotic epidemics urge us to critically reconsider our thinking on how to safeguard public health. Calls to include non-pathogenic interactions between microbes and hosts in our perspective on public health are gaining traction in the academic community (Cepon-Robins and Gildner, 2020). Here, we argue that this perspective should not only encompass an understanding of the microorganisms comprising the human ecosystem, but also those of other "non-human" ecosystems like animal, plants, water, and soil. As social norms influence innovation processes from both a push (e.g., what gets researched and developed) and pull (e.g., what is accepted by societal stakeholders) perspective, a thorough and early understanding of the societal impact of knowledge is important to guide and facilitate such processes (Van de Burgwal et al., 2018a; Hernando-Amado et al., 2020). This enables stakeholders to address unmet societal needs (Reperant et al., 2014; Van de Burgwal et al., 2016), to share and cooperate across the research and development process (Ribeiro et al., 2018; van der Waal et al., 2020), and to use best practices to prevent step-limiting roadblocks (van de Burgwal et al., 2018b; Flach et al., 2019).

\section{THE ROLE OF THE MICROBIOME IN HEALTH HOMEOSTASIS}

The human microbiota is increasingly acknowledged as one of the key players responsible for a robust and resilient healthy homeostasis, with "old friends" playing an essential role in the development and regulation of the mammalian immune system, host metabolism, and brain function (Ball et al., 2000; McDade et al., 2012; Rook et al., 2014; von Mutius, 2016; Hill and Round, 2021). With early life being commonly understood as a critical window for establishing a healthy microbiome (Cox et al., 2014), the acquisition and maintenance of essential microbial communities continue during adolescence and into adulthood (Riedler et al., 2001; Ege et al., 2008; Milo and Kahana, 2010; Rehman et al., 2010; Claesson et al., 2012). Indeed, the maintenance of a healthy gastrointestinal microbiome is considered critically dependent on the continuous acquisition of microorganisms and appropriate supporting substrates through food, water, air and other interactions with the environment (Dethlefsen et al., 2007; David et al., 2014).

The health of the human microbiota, however, is challenged through different mechanisms, with changes in microbial communities occurring in timescales as small as daily and as large as evolutionary (Banatvala et al., 1993; Hehemann et al., 2010; Yatsunenko et al., 2012). First, a decline or loss of certain species can be instigated as a result of external perturbations, such as antibiotic treatment and maladapted diets (David et al., 2014; Thorburn et al., 2014; Johnson et al., 2019). Second, improved hygiene has made it less likely that deficits are compensated through horizontal transmission, for example, fecal contamination of drinking waters or physical contact due to social crowding (Bach, 2021). Such lack of microbe replenishment has been correlated with frailty, upregulation of inflammatory markers, and reduced immune function (Claesson et al., 2012; Voorhies and Lorenzi, 2016). And third, opportunities for infants to acquire a healthy microbiome through vertical, that is, maternal transmission, are reduced as a result of these external perturbations and reduced horizontal transmission, compounding the effect (Blaser and Falkow, 2009; Pärnänen et al., 2018).

\section{RESILIENCE MEDIATED BY KEYSTONE TAXA AND MICROBIAL GUILDS}

While a resilient microbiome recovers from such temporary changes to microbial diversity, persistent changes of microbiome composition lead to progressive loss of microbiome diversity over generations (Dethlefsen and Relman, 2011; Lichtman et al., 2016; Sonnenburg et al., 2016). Throughout history, we see a number of transitions occurring, with human gut microbiomes loosing key strains, and becoming less diverse. Generally, Western populations are characterized by an overall reduced microbial diversity and stability in their gut microbiome, as compared to unindustrialized rural communities (De Filippo et al., 2010; Yatsunenko et al., 2012), with human gut microbiomes from non-industrialized societies closer resembling ancient feces microbiota (Olm and Sonnenburg, 2021). These differences translate to reduced functionality, with, for example, less diverse repertoires for utilizing carbohydrates (Smits et al., 2017). It is also proposed that such changes are a key driver for the rise in inflammatory diseases throughout the 20th and 21st century (Bach, 2002, 2018) and other complex multifactorial diseases (Virgin and Todd, 2011; Huttenhower et al., 2012; Lemon et al., 2012; Faith et al., 2013; Kreiner et al., 2017; Kolodziejczyk et al., 2019; von Mutius and Smits, 2020). While functional redundancy between species in the human gut microbiota can serve as an "insurance" against decreases in abundance or functionality of certain species (Elmqvist et al., 2003; Nicholson et al., 2012; Shafquat et al., 2014; Sommer et al., 2017), reduced diversity ultimately leads to reduced resilience of the gut microbiota.

On a mechanistic level, we have come to understand that this functional diversity is not only mediated by certain species, but by keystone taxa and microbial guilds. Keystone taxa are defined as "highly connected taxa that individually or in a guild exert a considerable influence on microbiome structure and functioning irrespective of their abundance across space and time. These taxa have a unique and crucial role in microbial communities, and their removal can cause a dramatic shift in microbiome structure and functioning." (Banerjee et al., 2018). The importance of keystone taxa is exemplified by the restoration of microbiome diversity that can be accomplished generations later by co-introduction of such keystone microbiota taxa with relevant dietary fibers (Sonnenburg et al., 2016). Microbial 
guilds, which microbial members may originate from different taxonomic backgrounds, are small ecosystems in which the individual taxa work together as coherent functional units or by exploiting the same class of resources (Wu et al., 2021). As guilds function as a single biological entity, the guilds in itself are expected to be particularly resilient. At the same time, simulations on hypothetical microbial guilds suggest that a decreased diversity within the guild leads to diminished efficiency of the physiological process the guild is dedicated to, as well as less stability (Larsen and Claassen, 2018). Using the microbial guild concept, it appears natural to extend the paradigm of functional diversity being related to the diversity of taxa further to the diversity of functional microbial guilds. As such, a higher functional diversity should be attributed to a higher diversity of functional microbial guilds, each guild dedicated to its own unique physiological process and hence its own functionality. Maintaining appropriate keystone taxa and "keystone guilds" can then be seen as necessary in order to safeguard both sufficient functional diversity as well as redundancy in functionalities enabling adequate compensation for possible losses in functional taxa and guilds.

\section{TIPPING POINTS AND CATASTROPHIC COLLAPSE}

Whereas most taxa in the human gut microbiome are characterized by gradual variation, a number of specific taxa are characterized by the existence of bistable states of low or high abundance (Lahti et al., 2014). These taxa can undergo an abrupt shift from a high-abundance to a low-abundance state. Interestingly, shifts across tipping points of one taxa are often associated with similar shifts in covarying taxa (Lahti et al., 2014). Placing this notion of keystone taxa and "keystone guilds" in an evolutionary perspective, the successive extinction (and acquisition) of functionalities (traits) may cause a "catastrophic collapse," leading to "abrupt and possibly irreversible shifts between alternative ecosystem states" (Dakos et al., 2019). Such large-scale collapses are characterized by "tipping points," across which the ecosystems tips toward an alternative state. Not unlike the guild concept, these taxa may represent "tipping elements," specific components that exhibit bistable states and are related to the overall health of the ecosystem (Lenton et al., 2008; Lahti et al., 2014).

Shifts across tipping points may be a consequence of disruptive selection, in which more extreme phenotypes have an advantage over intermediate phenotypes, be induced by environmentally or genetically determined host factors, or can occur as the result of ecological interactions between microbial communities (Rueffler et al., 2006; Faust and Raes, 2012). A proper assessment of current health problems like new pandemics and the rise of autoimmune indications can thus only be effective by incorporation of all (microbial) ecosystems involved, not being limited to our human microbiome alone. For example, a full comprehension of zoonotic disease requires not only understanding of the human microbiome but also of the microbial ecosystem belonging to the vector from which the pathogenic microorganism is being transferred, as also suggested by the concept of microbiota coalescence (Baquero et al., 2021). Analogously, health cannot be understood without a proper understanding of the ecosystem containing the old friends. For example, it was recently suggested that coinfection with soil-transmitted helminths may suppress the inflammatory response upon infection with SARS-CoV-2 (Cepon-Robins and Gildner, 2020). Hence, a full comprehension of our homeostasis (and threats to it) can only be reached through a broader perspective, in which the bidirectional interactions between the mutualistic microbial ecosystems involved (human gut, skin, animal, soil etc.) are being understood.

\section{A WIDER PERSPECTIVE: CO-OCCURRENCE PATTERNS IN A PLANETARY HEALTH CONTEXT}

The planetary health concept naturally urges for a wider view with respect to cherishing our old friends, which is indeed not limited to the human gut microbiota anymore. Just as microbiome communities within humans are characterized by their robustness and resilience, so are the broader ecosystems in which we live (McFall-Ngai et al., 2013). Paradoxically, while the widespread use of antibiotics has led to the propagation of antimicrobial resistance genes as well as increased density of mobile genetic elements, implying accelerated evolutionary rates (Baquero, 2021), changes in our way of living have led to reduced replenishments of symbiotic bacteria. Indeed, not only contact with microbiota from other humans and animals are of relevance, so are material and urban microbial populations, which are indicated to play a role in, for example, "sick building syndrome" (Sahlberg et al., 2010) and antimicrobial resistance (Danko et al., 2021). The planetary health concept underscores the close relation between human health within a flourishing natural system, propagating across-ecosystem approaches to understand the links between health and environmental change (Whitmee et al., 2015).

The possibility of a future catastrophic collapse, through the role of the environmental microbiome in the development and propagation of antibiotic resistance genes, is now broadly recognized (Robinson et al., 2016; Jørgensen et al., 2018; Thakur and Gray, 2019). Attention has been given to less biodiverse human environments, and a need to "Rewild" urban green spaces, allowing interactions with beneficial microbiome in the direct environment of humans (Mills et al., 2017). Green space exposure has been shown to increase diversity in skin and nasal microbiota (Selway et al., 2020). Likewise, living in close proximity to natural environments has been linked to mental health - a relation that may, at least in part, be mediated by contact with environmental microbiota (Flandroy et al., 2018).

Co-occurrence patterns within and between microbial communities, however, have to-date been relatively sparsely studied (Williams et al., 2014; Klimenko et al., 2020). In addition, the research on critical transitions in the gut microbiome is still in its early stages and primarily related to the gut 


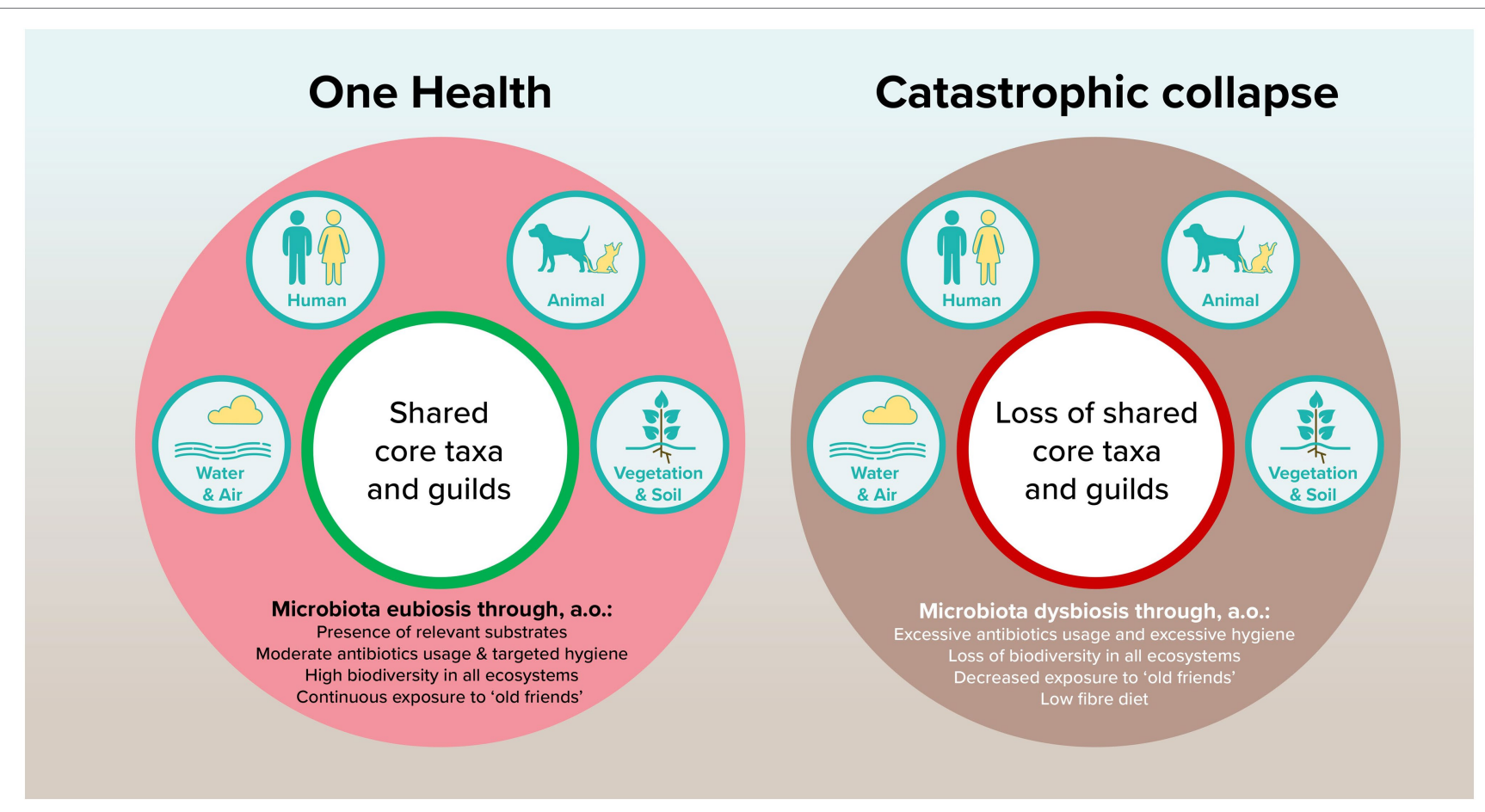

FIGURE 1 | Proposed model of how shared core taxa and guilds can contribute to planetary health through microbiota eubiosis.

microbiome within individuals (Tytgat et al., 2019; Malard et al., 2020). Moreover, modeling microbial communities are still faced with numerous challenges (Faust and Raes, 2012; Gil-Gil et al., 2021). A step beyond, manipulating and engineering microbial communities, a process described as synthetic ecology, is even more early stage (Dunham, 2007; Zomorrodi and Segrè, 2016). Whereas some research has studied the role of keystone taxa in critical transitions in water microbiomes (Wang et al., 2020), their role is not yet described in critical transitions within host microbiomes nor in gut microbiomes across the human species.

\section{DISCUSSION}

Following all this, we advocate the investment in strong research efforts toward the identification of keystone taxa and (keystone) microbial guilds that interconnect the different domains (ranging from human, animal, soil, water, and other environmental domains), altogether responsible for a balanced ecosystem that is both robust toward potential communicable and non-communicable disease, as to the minimization of pathogenic transmissions between these domains. A key question in microbiota research is whether such interventions can sustainably remodel disease-prone microbiota compositions to robust and resilient healthy microbiota compositions (Sanders et al., 2013). Probiotic microorganisms can then be regarded as "supplemental keystone taxa." Improved mechanistic understanding of factors that shape structure and function is needed to further design interventions with pre- and probiotics (Bäckhed et al., 2012).

A first prerequisite for such a rational approach toward intervention is a better understanding of the microbial interaction network, both within species and between species. The subdivision of the interactions between mutualistic ecosystems into different subsets each characterized by a topological parameter like the $k$-core [a $k$-core indicates that all nodes (taxa) of the associated subgraph have a direct connection to at least $k$ nodes] is demonstrated to be a highly useful parameter. In particular, taxa belonging to the maximum $k$-core (highest connectivity) are crucial for the ecosystems stability, and removal of these taxa results in a total collapse of the complete network (Morone et al., 2019). We propose that the same may account for microbial guilds: keystone guilds will have highest connectivity to other guilds and should also be cherished to prevent possible catastrophic collapses. In addition, replenishment of additional species may be supportive to the formation and maintenance of these keystone guilds.

A second prerequisite is the identification of early warning signs for a catastrophic collapse, warranting a timely response for intervention. Such early warning signs have been described in detail (Scheffer et al., 2009), and include a slowing down of the system (exemplified by, a slower recovery of the ecosystem to its original state after an external perturbation, increased autocorrelation, and increased variance in the pattern of fluctuations of the ecosystem). All the aforementioned should be taken into perspective when 
monitoring changes in gut health. As such, the identification of these topological parameters and warning signs will enable us to selectively target the restoration and reinforcement of these entities in order to prevent an outbalanced ecosystem leading to a possible overall catastrophic collapse.

\section{CONCLUSION}

We should not forget that mutualism and pathogenicity are two sides of the same coin, see Figure 1. Whereas currently much attention has been given to the risk of zoonotic pathogens, we must be careful to not isolate ourselves from our microbial environment. The evolution in the human microbiome that is visible over decades and across populations is a starting point to investigate the resilience and robustness of healthy human gut microbiomes. Without careful consideration, we may be on the verge of a catastrophic collapse on a population level, leading to functional decline of gut ecosystems. Building upon the planetary health concept, we argue that research on the microbiome should not only focus on the individual level through personalized approaches, but even more on the system level to conserve ecosystem resilience.

\section{REFERENCES}

Bach, J.-F. (2002). The effect of infections on susceptibility to autoimmune and allergic diseases. N. Engl. J. Med. 347, 911-920. doi: 10.1056/NEJMra020100

Bach, J. F. (2018). The hygiene hypothesis in autoimmunity: the role of pathogens and commensals. Nat. Rev. Immunol. 18, 105-120. doi: 10.1038/nri.2017.111

Bach, J.-F. (2021). Revisiting the hygiene hypothesis in the context of autoimmunity. Front. Immunol. 11:615192. doi: 10.3389/fimmu.2020.615192

Bäckhed, F., Fraser, C. M., Ringel, Y., Sanders, M. E., Sartor, R. B., Sherman, P. M., et al. (2012). Defining a healthy human gut microbiome: current concepts, future directions, and clinical applications. Cell Host Microbe 12, 611-622. doi: 10.1016/j.chom.2012.10.012

Ball, T. M., Castro-Rodriguez, J. A., Griffith, K. A., Holberg, C. J., Martinez, F. D., and Wright, A. L. (2000). Siblings, day-care attendance, and the risk of asthma and wheezing during childhood. N. Engl. J. Med. 343, 538-543. doi: 10.1056/NEJM200008243430803

Banatvala, N., Mayo, K., Megraud, F., Jennings, R., Deeks, J., and Feldman, R. (1993). The cohort effect and helicobacter pylori. J. Infect. Dis. 168, 219-221. doi: 10.1093/infdis/168.1.219

Banerjee, S., Schlaeppi, K., and van der Heijden, M. G. A. (2018). Keystone taxa as drivers of microbiome structure and functioning. Nat. Rev. Microbiol. 16, 567-576. doi: 10.1038/s41579-018-0024-1

Baquero, F. (2021). Threats of antibiotic resistance: an obliged reappraisal. Int. Microbiol. 1-8. doi: 10.1007/s10123-021-00184-y

Baquero, F., Coque, T. M., Galán, J. C., and Martinez, J. L. (2021). The origin of niches and species in the bacterial world. Front. Microbiol. 12:657986. doi: 10.3389/fmicb.2021.657986 [Epub ahead of print]

Blaser, M. J., and Falkow, S. (2009). What are the consequences of the disappearing human microbiota? Nat. Rev. Microbiol. 7, 887-894. doi: 10.1038/nrmicro2245

Cepon-Robins, T. J., and Gildner, T. E. (2020). Old friends meet a new foe: A potential role for immune-priming parasites in mitigating COVID-19 morbidity and mortality. Evol. Med. Public Health 2020, 234-248. doi: 10.1093/ emph/eoaa037

Claesson, M. J., Jeffery, I. B., Conde, S., Power, S. E., O’Connor, E. M., Cusack, S., et al. (2012). Gut microbiota composition correlates with diet and health in the elderly. Nature 488, 178-184. doi: 10.1038/nature11319

\section{DATA AVAILABILITY STATEMENT}

The original contributions presented in the study are included in the article/supplementary material, and further inquiries can be directed to the corresponding author.

\section{AUTHOR CONTRIBUTIONS}

OL: conceptualization, formal analysis, and writing - review and editing. LB: conceptualization and writing - original draft. All authors contributed to the article and approved the submitted version.

\section{FUNDING}

This publication is partly financed by the project Preparedness for Emerging Infectious Diseases (with project number VI.Veni.201S.044 of the research programme Veni SGW which is financed by the Dutch Research Council (NWO). The funding source had no involvement in study design, data collection, data analysis, interpretation of the data, writing of the report or the decision to submit the article for publication.

Cox, L. M., Yamanishi, S., Sohn, J., Alekseyenko, A. V., Leung, J. M., Cho, I., et al. (2014). Altering the intestinal microbiota during a critical developmental window has lasting metabolic consequences. Cell 158, 705-721. doi: 10.1016/j. cell.2014.05.052

Dakos, V., Matthews, B., Hendry, A. P., Levine, J., Loeuille, N., Norberg, J., et al. (2019). Ecosystem tipping points in an evolving world. Nat. Ecol. Evol. 3, 355-362. doi: 10.1038/s41559-019-0797-2

Danko, D., Bezdan, D., Afshin, E. E., Ahsanuddin, S., Bhattacharya, C., Butler, D. J., et al. (2021). A global metagenomic map of urban microbiomes and antimicrobial resistance. Cell 184, 3376-3393.e17. doi: 10.1016/j.cell.2021.05.002

David, L. A., Materna, A. C., Friedman, J., Campos-Baptista, M. I., Blackburn, M. C., Perrotta, A., et al. (2014). Host lifestyle affects human microbiota on daily timescales. Genome Biol. 15:R89. doi: 10.1186/gb-2014-15-7-r89

De Filippo, C., Cavalieri, D., Di Paola, M., Ramazzotti, M., Poullet, J. B., Massart, S., et al. (2010). Impact of diet in shaping gut microbiota revealed by a comparative study in children from Europe and rural Africa. Proc. Natl. Acad. Sci. 107, 14691-14696. doi: 10.1073/pnas.1005963107

Dethlefsen, L., McFall-Ngai, M., and Relman, D. A. (2007). An ecological and evolutionary perspective on human-microbe mutualism and disease. Nature 449, 811-818. doi: 10.1038/nature06245

Dethlefsen, L., and Relman, D. A. (2011). Incomplete recovery and individualized responses of the human distal gut microbiota to repeated antibiotic perturbation. Proc. Natl. Acad. Sci. 108(Suppl. 1), 4554-4561. doi: 10.1073/ pnas. 1000087107

Dunham, M. J. (2007). Synthetic ecology: A model system for cooperation. Proc. Natl. Acad. Sci. 104, 1741-1742. doi: 10.1073/pnas.0611067104

Ege, M. J., Herzum, I., Büchele, G., Krauss-Etschmann, S., Lauener, R. P., Roponen, M., et al. (2008). Prenatal exposure to a farm environment modifies atopic sensitization at birth. J. Allergy Clin. Immunol. 122, 407-412.e4. doi: 10.1016/j.jaci.2008.06.011

Elmqvist, T., Folke, C., Nyström, M., Peterson, G., Bengtsson, J., Walker, B., et al. (2003). Response diversity, ecosystem change, and resilience. Front Ecol. Environ. 1, 488-494. doi: 10.1890/1540-9295(2003)001[0488:RDECAR] 2.0.CO;2

Faith, J. J., Guruge, J. L., Charbonneau, M., Subramanian, S., Seedorf, H., Goodman, A. L., et al. (2013). The long-term stability of the human gut microbiota. Science 341:1237439. doi: 10.1126/science.1237439 
Faust, K., and Raes, J. (2012). Microbial interactions: from networks to models. Nat. Rev. Microbiol. 10, 538-550. doi: 10.1038/nrmicro2832

Flach, J., Ribeiro, C. D. S., van der Waal, M. B., van der Waal, R. X., Claassen, E., and van de Burgwal, L. H. M. (2019). The Nagoya protocol on access to genetic resources and benefit sharing: best practices for users of lactic acid bacteria. PharmaNutrition 9:100158. doi: 10.1016/j.phanu.2019.100158

Flandroy, L., Poutahidis, T., Berg, G., Clarke, G., Dao, M.-C., Decaestecker, E., et al. (2018). The impact of human activities and lifestyles on the interlinked microbiota and health of humans and of ecosystems. Sci. Total Environ. 627, 1018-1038. doi: 10.1016/j.scitotenv.2018.01.288

Gil-Gil, T., Ochoa-Sánchez, L. E., Baquero, F., and Martínez, J. L. (2021). Antibiotic resistance: time of synthesis in a post-genomic age. Comput. Struct. Biotechnol. J. 19, 3110-3124. doi: 10.1016/j.csbj.2021.05.034

Hehemann, J.-H., Correc, G., Barbeyron, T., Helbert, W., Czjzek, M., and Michel, G. (2010). Transfer of carbohydrate-active enzymes from marine bacteria to Japanese gut microbiota. Nature 464, 908-912. doi: 10.1038/ nature 08937

Hernando-Amado, S., Coque, T. M., Baquero, F., and Martínez, J. L. (2020). Antibiotic resistance: moving from individual health norms to social norms in one health and global health. Front. Microbiol. 11:1914. doi: 10.3389/ fmicb.2020.01914

Hill, J. H., and Round, J. L. (2021). SnapShot: microbiota effects on host physiology. Cell 184:2796.e2791. doi: 10.1016/j.cell.2021.04.026

Huttenhower, C. D., Gevers, R., Knight, S., Abubucker, J. H., Badger, A. T., Chinwalla, H. H., et al. (2012). Structure, function and diversity of the healthy human microbiome. Nature 486, 207-214. doi: 10.1038/nature11234

Johnson, A. J., Vangay, P., Al-Ghalith, G. A., Hillmann, B. M., Ward, T. L., Shields-Cutler, R. R., et al. (2019). Daily sampling reveals personalized dietmicrobiome associations in humans. Cell Host Microbe 25, 789-802.e5. doi: 10.1016/j.chom.2019.05.005

Jørgensen, P. S., Aktipis, A., Brown, Z., Carrière, Y., Downes, S., Dunn, R. R., et al. (2018). Antibiotic and pesticide susceptibility and the Anthropocene operating space. Nat. Sustain. 1, 632-641. doi: 10.1038/s41893-018-0164-3

Klimenko, N. S., Tyakht, A. V., Toshchakov, S. V., Shevchenko, M. A., Korzhenkov, A. A., Afshinnekoo, E., et al. (2020). Co-occurrence patterns of bacteria within microbiome of Moscow subway. Comput. Struct. Biotechnol. J. 18, 314-322. doi: 10.1016/j.csbj.2020.01.007

Kolodziejczyk, A. A., Zheng, D., and Elinav, E. (2019). Diet-microbiota interactions and personalized nutrition. Nat. Rev. Microbiol. 17, 742-753. doi: 10.1038/ s41579-019-0256-8

Kreiner, E., Waage, J., Standl, M., Brix, S., Pers, T. H., Alves, A. C., et al. (2017). Shared genetic variants suggest common pathways in allergy and autoimmune diseases. J. Allergy Clin. Immunol. 140, 771-781. doi: 10.1016/j. jaci.2016.10.055

Lahti, L., Salojärvi, J., Salonen, A., Scheffer, M., and de Vos, W. M. (2014). Tipping elements in the human intestinal ecosystem. Nat. Commun. 5:5344. doi: $10.1038 /$ ncomms5344

Larsen, O. F. A., and Claassen, E. (2018). The mechanistic link between health and gut microbiota diversity. Sci. Rep. 8:2183. doi: 10.1038/s41598-018-20141-6

Lemon, K. P., Armitage, G. C., Relman, D. A., and Fischbach, M. A. (2012). Microbiota-targeted therapies: An ecological perspective. Sci. Transl. Med. 4:137rv5. doi: 10.1126/scitranslmed.3004183

Lenton, T. M., Held, H., Kriegler, E., Hall, J. W., Lucht, W., Rahmstorf, S., et al. (2008). Tipping elements in the Earth's climate system. Proc. Natl. Acad. Sci. 105, 1786-1793. doi: 10.1073/pnas.0705414105

Lichtman, J. S., Ferreyra, J. A., Ng, K. M., Smits, S. A., Sonnenburg, J. L., and Elias, J. E. (2016). Host-microbiota interactions in the pathogenesis of antibiotic-associated diseases. Cell Rep. 14, 1049-1061. doi: 10.1016/j. celrep.2016.01.009

Malard, F., Dore, J., Gaugler, B., and Mohty, M. (2020). Introduction to host microbiome symbiosis in health and disease. Mucosal Immunol. 14, 547-554.

McDade, T. W., Tallman, P. S., Madimenos, F. C., Liebert, M. A., Cepon, T. J., Sugiyama, L. S., et al. (2012). Analysis of variability of high sensitivity C-reactive protein in lowland Ecuador reveals no evidence of chronic lowgrade inflammation. Am. J. Hum. Biol. 24, 675-681. doi: 10.1002/ajhb.22296

McFall-Ngai, M., Hadfield, M. G., Bosch, T. C. G., Carey, H. V., Domazet-Lošo, T., Douglas, A. E., et al. (2013). Animals in a bacterial world, a new imperative for the life sciences. Proc. Natl. Acad. Sci. 110, 3229-3236. doi: 10.1073/ pnas. 1218525110
Mills, J. G., Weinstein, P., Gellie, N. J. C., Weyrich, L. S., Lowe, A. J., and Breed, M. F. (2017). Urban habitat restoration provides a human health benefit through microbiome rewilding: the microbiome Rewilding hypothesis. Restor. Ecol. 25, 866-872. doi: 10.1111/rec.12610

Milo, R., and Kahana, E. (2010). Multiple sclerosis: Geoepidemiology, genetics and the environment. Autoimmun. Rev. 9, A387-A394. doi: 10.1016/j. autrev.2009.11.010

Morone, F., Del Ferraro, G., and Makse, H. A. (2019). The k-core as a predictor of structural collapse in mutualistic ecosystems. Nat. Phys. 15, 95-102. doi: 10.1038/s41567-018-0304-8

Nicholson, J. K., Holmes, E., Kinross, J., Burcelin, R., Gibson, G., Jia, W., et al. (2012). Host-gut microbiota metabolic interactions. Science 336, 1262-1267. doi: $10.1126 /$ science. 1223813

Olm, M. R., and Sonnenburg, J. L. (2021). Ancient human faeces reveal gut microbes of the past. Nature 594, 182-183. doi: 10.1038/d41586-021-01266-7

Pärnänen, K., Karkman, A., Hultman, J., Lyra, C., Bengtsson-Palme, J., Larsson, D. G. J., et al. (2018). Maternal gut and breast milk microbiota affect infant gut antibiotic resistome and mobile genetic elements. Nat. Commun. 9:3891. doi: 10.1038/s41467-018-06393-w

Rehman, A., Lepage, P., Nolte, A., Hellmig, S., Schreiber, S., and Ott, S. J. (2010). Transcriptional activity of the dominant gut mucosal microbiota in chronic inflammatory bowel disease patients. J. Med. Microbiol. 59, 1114-1122. doi: 10.1099/jmm.0.021170-0

Reperant, L. A., van de Burgwal, L. H. M., Claassen, E., and Osterhaus, A. D. (2014). Ebola: public-private partnerships. Science 346, 433-434. doi: 10.1126/ science.346.6208.433-b

Ribeiro, C. D. S., Koopmans, M. P., and Haringhuizen, G. B. (2018). Threats to timely sharing of pathogen sequence data. Science 362, 404-406. doi: $10.1126 /$ science.aau5229

Riedler, J., Braun-Fahrländer, C., Eder, W., Schreuer, M., Waser, M., Maisch, S., et al. (2001). Exposure to farming in early life and development of asthma and allergy: a cross-sectional survey. Lancet 358, 1129-1133. doi: 10.1016/ S0140-6736(01)06252-3

Robinson, T. P., Bu, D. P., Carrique-Mas, J., Fèvre, E. M., Gilbert, M., Grace, D., et al. (2016). Antibiotic resistance is the quintessential one health issue Trans. R. Soc. Trop. Med. Hyg. 110, 377-380. doi: 10.1093/trstmh/trw048

Rook, G. A. W., Raison, C. L., and Lowry, C. A. (2014). Microbial 'old friends', immunoregulation and socioeconomic status. Clini. Exp. Immun. 177, 1-12. doi: $10.1111 /$ cei.12269

Rueffler, C., Van Dooren, T. J. M., Leimar, O., and Abrams, P. A. (2006). Disruptive selection and then what? Trends Ecol. Evol. 21, 238-245. doi: 10.1016/j.tree.2006.03.003

Sahlberg, B., Wieslander, G., and Norbäck, D. (2010). Sick building syndrome in relation to domestic exposure in Sweden-A cohort study from 1991 to 2001. Scand. J. Public Health 38, 232-238. doi: 10.1177/1403494809350517

Sanders, M. E., Guarner, F., Guerrant, R., Holt, P. R., Quigley, E. M. M., Sartor, R. B., et al. (2013). An update on the use and investigation of probiotics in health and disease. Gut 62, 787-796. doi: 10.1136/ gutjnl-2012-302504

Scheffer, M., Bascompte, J., Brock, W. A., Brovkin, V., Carpenter, S. R., Dakos, V., et al. (2009). Early-warning signals for critical transitions. Nature 461, 53-59. doi: $10.1038 /$ nature 08227

Selway, C. A., Mills, J. G., Weinstein, P., Skelly, C., Yadav, S., Lowe, A., et al. (2020). Transfer of environmental microbes to the skin and respiratory tract of humans after urban green space exposure. Environ. Int. 145:106084. doi: 10.1016/j.envint.2020.106084

Shafquat, A., Joice, R., Simmons, S. L., and Huttenhower, C. (2014). Functional and phylogenetic assembly of microbial communities in the human microbiome. Trends Microbiol. 22, 261-266. doi: 10.1016/j.tim.2014.01.011

Smits, S. A., Leach, J., Sonnenburg, E. D., Gonzalez, C. G., Lichtman, J. S., Reid, G., et al. (2017). Seasonal cycling in the gut microbiome of the Hadza hunter-gatherers of Tanzania. Science 357, 802-806. doi: 10.1126/science. an 4834

Sommer, F., Anderson, J. M., Bharti, R., Raes, J., and Rosenstiel, P. (2017). The resilience of the intestinal microbiota influences health and disease. Nat. Rev. Microbiol. 15, 630-638. doi: 10.1038/nrmicro.2017.58

Sonnenburg, E. D., Smits, S. A., Tikhonov, M., Higginbottom, S. K., Wingreen, N. S., and Sonnenburg, J. L. (2016). Diet-induced extinctions in the gut microbiota compound over generations. Nature 529, 212-215. doi: 10.1038/nature16504 
Thakur, S., and Gray, G. C. (2019). The mandate for a global one health approach to antimicrobial resistance surveillance. Am. J. Trop. Med. Hyg. 100, 227-228. doi: 10.4269/ajtmh.18-0973

Thorburn, A. N., Macia, L., and Mackay, C. R. (2014). Diet, metabolites, and "Western-lifestyle" inflammatory diseases. Immunity 40, 833-842. doi: 10.1016/j. immuni.2014.05.014

Tytgat, H. L. P., Nobrega, F. L., van der Oost, J., and de Vos, W. M. (2019). Bowel biofilms: tipping points between a healthy and compromised gut? Trends Microbiol. 27, 17-25. doi: 10.1016/j.tim.2018.08.009

Van de Burgwal, L. H., Reperant, L. A., Osterhaus, A. D., Iancu, S. C., Pronker, E. S., and Claassen, E. (2016). Self-centric and altruistic unmet needs for Ebola: barriers to international preparedness. Disaster Med. Public Health Prep. 10, 644-648. doi: 10.1017/dmp.2016.64

Van de Burgwal, L. H. M., Van der Waal, M. B., and Claassen, E. (2018a). Accelerating microbiota product development: The societal impact value cycle as a conceptual model to shape and improve public-private valorization processes. PharmaNutrition 6, 157-168. doi: 10.1016/j.phanu.2018.07.002

van de Burgwal, L. H., van Dorst, P., Viëtor, H., Luttge, R., and Claassen, E. (2018b). Hybrid business models for 'Organ-on-a-Chip'technology: The best of both worlds. PharmaNutrition 6, 55-63.

van der Waal, M. B., Ribeiro, C. D. S., Ma, M., Haringhuizen, G. B., Claassen, E., and van de Burgwal, L. H. M. (2020). Blockchain-facilitated sharing to advance outbreak R\&D. Science 368, 719-721. doi: 10.1126/science.aba1355

Virgin, H. W., and Todd, J. A. (2011). Metagenomics and personalized medicine. Cell 147, 44-56. doi: 10.1016/j.cell.2011.09.009

von Mutius, E. (2016). The microbial environment and its influence on asthma prevention in early life. J. Allergy Clin. Immunol. 137, 680-689. doi: 10.1016/j. jaci.2015.12.1301

von Mutius, E., and Smits, H. H. (2020). Primary prevention of asthma: from risk and protective factors to targeted strategies for prevention. Lancet 396, 854-866. doi: 10.1016/S0140-6736(20)31861-4

Voorhies, A. A., and Lorenzi, H. A. (2016). The challenge of maintaining a healthy microbiome during long-duration space missions. Front. Astron. Space Sci. 3:23. doi: 10.3389/fspas.2016.00023

Wang, B., Zheng, X., Zhang, H., Xiao, F., He, Z., and Yan, Q. (2020). Keystone taxa of water microbiome respond to environmental quality and predict water contamination. Environ. Res. 187:109666. doi: 10.1016/j.envres. 2020.109666

Whitmee, S., Haines, A., Beyrer, C., Boltz, F., Capon, A. G., de Souza Dias, B. F., et al. (2015). Safeguarding human health in the Anthropocene epoch: report of The Rockefeller Foundation-lancet commission on planetary health. Lancet 386, 1973-2028. doi: 10.1016/S0140-6736(15)60901-1

Williams, R. J., Howe, A., and Hofmockel, K. S. (2014). Demonstrating microbial co-occurrence pattern analyses within and between ecosystems. Front. Microbiol. 5:358. doi: $10.3389 /$ fmicb. 2014.00358

Wu, G., Zhao, N., Zhang, C., Lam, Y. Y., and Zhao, L. (2021). Guild-based analysis for understanding gut microbiome in human health and diseases. Genome Med. 13, 1-12. doi: 10.1186/s13073-021-00840-y

Yatsunenko, T., Rey, F. E., Manary, M. J., Trehan, I., Dominguez-Bello, M. G., Contreras, M., et al. (2012). Human gut microbiome viewed across age and geography. Nature 486, 222-227. doi: 10.1038/nature11053

Zomorrodi, A. R., and Segrè, D. (2016). Synthetic ecology of microbes: mathematical models and applications. J. Mol. Biol. 428, 837-861. doi: 10.1016/j.jmb.2015.10.019

Conflict of Interest: OL is also Senior Manager Science at Yakult. LB is consultant for several commercial parties in the field of probiotics and life sciences; none of her advising practices are related to or in conflict with the content of this research.

Publisher's Note: All claims expressed in this article are solely those of the authors and do not necessarily represent those of their affiliated organizations, or those of the publisher, the editors and the reviewers. Any product that may be evaluated in this article, or claim that may be made by its manufacturer, is not guaranteed or endorsed by the publisher.

Copyright (c) 2021 Larsen and van de Burgwal. This is an open-access article distributed under the terms of the Creative Commons Attribution License (CC BY).

The use, distribution or reproduction in other forums is permitted, provided the original author(s) and the copyright owner(s) are credited and that the original publication in this journal is cited, in accordance with accepted academic practice. No use, distribution or reproduction is permitted which does not comply with these terms. 